\title{
Nota como exemplar textual do discurso de uma mídia corporativa
}

institucional.us.es/ambitos/

\section{Marta Cardoso de Andrade}

Universidade Salvador - UNIFACS

marta.andrade@unifacs.br

\author{
Hélder Uzêda Castro \\ Faculdade Ruy Barbosa - FRB \\ hcastro@frb.edu.br
}

English Version: Clipping showing the textual criticism of a corporative media speech

\section{Resumo}

As produções textuais delimitadas num período discutem assuntos de interesses específicos do público, de forma geral ou de segmentos específicos deste. Nas empresas, isso não ocorre de forma diferente. Daí ser imprescindível produzir textos numa linha argumentativa eficaz/eficiente e construir um discurso que convença o auditório ao qual se destina. Para compreensão desse fenômeno, analisou-se a construção do ethos e da situação enunciativa, o uso dos argumentos e dos elementos linguísticos reveladores do discurso existente numa nota de revista empresarial. Dessa forma, foi usado como aporte teórico: Comunicação Organizacional, da Retórica/Nova Retórica e da Análise do Discurso de linha

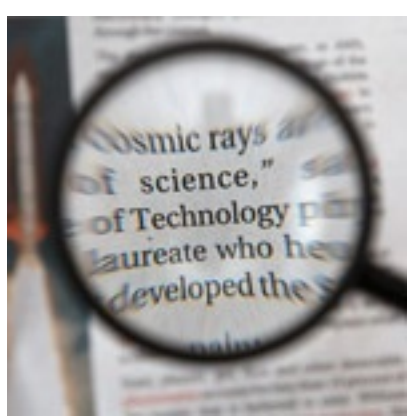

francesa.

\section{Palavras Chave}

Discurso, nota, comunicação, relações públicas.

Abstract

Texts enclosed in a period discuss matters of specific interests of the public in general or specific segments of this. In companies this does not occur differently. Hence it is essential to produce texts in an effective/efficient line of argument and build a speech to convince the audience to which it is intended. To understand this phenomenon, it analyzed the construction of the ethos and enunciation situation, the use of arguments and revealing linguistic elements of the existing note speech at a business magazine. Thus, it was used as theoretical framework: Organizational Communication, Rhetoric/New Rhetoric and French Line Discourse Analysis.

\section{Keywords}

Discurse, note, communication, public relation.

\section{INTRODUÇÃO}

Numa sociedade na qual a Comunicação se torna cada vez mais importante, vive-se um momento único: o mundo está globalizado, concretizou-se a profecia, feita nos meados do século XX, da "aldeia global" de McLuhan (1969: 95). Os seres humanos estão cada vez mais imersos num "arsenal"/"bombardeio" de informações e canais para que essas se estabeleçam, outrossim, muitos direitos foram conseguidos no século passado e no início deste. Saber e lutar por essas e outras conquistas é uma atitude cotidiana. Isso, entretanto, se tornou mais fácil para o homem hodierno, uma vez que esse está inserido numa sociedade dita, como já foi mencionado, de comunicação, na qual as informações circulam com uma velocidade assustadora, pode-se até dizer que é simultânea ao acontecimento. 
Partindo-se desse pressuposto e da necessidade de se analisar texto/discursos presentes no cotidiano e circulantes na sociedade atual, principalmente os produzidos pelas organizações, as quais estão cada vez mais presentes no cotidiano dos seres humanos, escolheu-se trabalhar com uma nota de uma revista empresarial publicada por uma instituição bancária privada que teve expressiva representatividade no mercado brasileiro. Para tanto, foi utilizado como aporte teórico pressupostos da Comunicação Organizacional/Relações Publicas, da Retórica/Nova Retórica e da Análise do Discurso de linha francesa.

Para empreender este estudo, far-se-á a seguir um pequeno percurso teórico acerca dos principais tópicos que foram abordados na análise realizada, a qual aparece logo em seguida, por fim, são levantadas as considerações finais chegadas ao final deste trabalho.

\section{VISITANDO A TEORIA}

Debater tornou-se uma necessidade de expressão constante, bem como urge a defesa de ideias e pontos de vistas, como também o agradar, seduzir, persuadir e convencer os outros membros do grupo ao qual se faz parte. As produções textuais, como também os discursos circulantes, aparecem igualmente redarguindo a esses temas inquietantes existentes nesses grupos. Em resposta a essa atual e emergente demanda, resgatam-se conhecimentos da Retórica, área do conhecimento humano legada pelos gregos na Antiguidade Clássica. Um dos seus maiores pensadores, Aristóteles ([V a.C.] 1998:. 22), a conceituava como sendo um campo do saber responsável pela "(...) arte da comunicação, do discurso feito em público com fins persuasivos", outrossim, pode ser entendida como a capacidade de descobrir o que é adequado a cada caso em específico cuja finalidade é trazer o ouvinte/interlocutor para o seu favor, fazendo com que esse adote o seu ponto de vista.

A maior inovação impressa por Aristóteles, apontada por três estudiosos da Retórica da atualidade - Meyer, Carrilho e Timmermans (2002: 50) - está na “(..) sistematicidade através da qual esse pensador grego integra os três elementos fundamentais do discurso", os quais são: o ethos - quem fala, o logos - argumento apresentado, e o pathos - a quem se dirige. Cada um desses desempenha um papel fundamental, que se complementa com o dos outros numa articulação complexa (llustração 1). A partir desses, Aristóteles ainda afirmou que a persuasão fornecida pelo discurso pode ser de três espécies: a que reside no caráter moral do orador, ou seja, no ethos; a advinda do modo como se dispõe o ouvinte, ou seja, focalizadas no pathos; e, por fim, a centrada no próprio discurso devido àquilo que este demonstra ou parece demonstrar, ou seja, no logos.

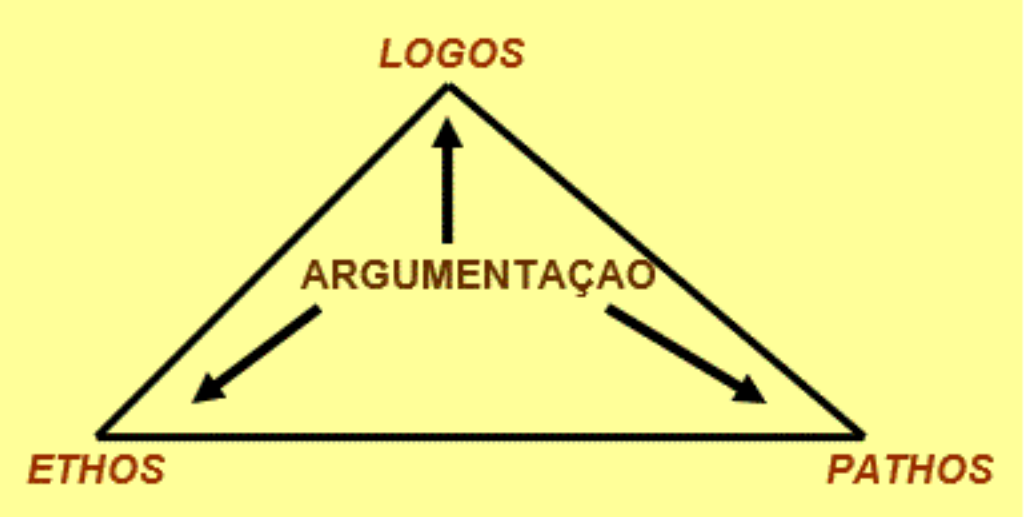

Ilustração 1 - Articulação entre os três elementos da persuasão

Fonte: Adam (2005: 94)

Meyer (1993 apud Meyer; Carrilho; Timmermans, 2002: 54) explica, de modo bem sucinto, como cada um desses três elementos funciona na já citada articulação:

Se nos colocarmos na perspectiva do orador, é a vontade de agradar, de persuadir, de seduzir, de convencer que se impõe como determinante, pouco importando se tal se faz através de belos discursos ou argumentos racionais. Se encararmos agora a perspectiva do auditório, o que conta é sobretudo (sic) a decodificação das 
intenções e, assim, o carácter do orador, a inferência que se pode fazer a partir do que é enunciado literalmente. Resta, por fim, a terceira perspectiva: a do próprio médium, a linguagem ou a imagem, em suma, a mensagem. Aqui, o que conta são as marcas do implícito sugerido, o sentido lingüístico e as condições pragmáticas da sua ocorrência, os tipos de discurso utilizados, a narração, o texto ou o argumentário.

Para efeitos deste estudo, enfocar-se-á apenas o primeiro desses casos de persuasão. Devido às demandas contemporâneas da sociedade, o orador/escritor deve imbuir-se de certas qualidades, ou melhor, para se conseguir persuadir pelo caráter, o discurso deve ser montado/proferido de tal forma a passar a impressão de que o orador é digno de fazê-lo. Ainda seguindo a linha de raciocínio de Aristóteles, esse acreditava que o homem está sempre mais propenso a acreditar, com maior firmeza e convicção e também mais rápido, em pessoas tidas como de bem e honestas. Assim, um dos segredos da persuasão está no orador passar uma imagem favorável de si mesmo, imagem essa que deve seduzir o auditório/pathos e captar a benevolência e a simpatia deste. Essa representação do orador é o próprio ethos. Este equivale ao caráter que o orador atribui a si mesmo pelo modo como exerce sua atividade retórica: com um tipo específico de fluência; de entonação calorosa ou severa; da escolha das palavras e dos argumentos (o fato de escolher ou de negligenciar um argumento em específico pode parecer sintomático de uma qualidade ou de um defeito); ou até daquilo que não foi dito. O ethos termina por funcionar como um elemento que reforçaria a plausibilidade da argumentação exposta, o que, não se deve tanto aos aspectos morais do orador, mas sim àquilo que é resultado do próprio discurso desse. Portanto, o que é vital, neste tocante, é que a confiança imputada no orador seja um "efeito" do discurso desse.

Para que o ethos seja bem construído, há outra noção, que lhe é correlata e deve ser considerada. Essa é o páthos, ou melhor, o auditório. Este e o orador sevem para se referir, respectivamente, aos pólos de recepção e produção dos discursos. Perelman e Olbrechts-Tyteca (2002: 7) advertem que "(...) se quiser agir, o orador é obrigado a adaptar-se a seu auditório". Portanto, sobre os conteúdos do discurso, o orador deve ter conhecimento sobre aqueles que ouvirão para conseguir ter sucesso no seu intento persuasivo.

Destaca-se ainda o conceito de face de Goffman (in Amossy, 2005: 13) definida como “(...) valor social positivo que dado indivíduo efetivamente reivindica por meio da linha de ação que os outros supõem que ele adotou durante um contato particular". Dessa maneira, a face seria uma imagem do eu (= ethos), "(...) delineada, segundo certos atributos sociais aprovados e, apesar disso, partilháveis, uma vez que podemos, por exemplo, causar uma boa imagem de nossa profissão ou de nossa fé quando causamos uma boa imagem de nós mesmos" (Goffman in Amossy, 2005: 13). Ainda segundo Amossy (2005: 13), Goffman abriu, em seus estudos, a perspectivas dos comportamentos na vida cotidiana que foram retomadas pela descrição das trocas verbais, na qual elas permitem destacar que "(...) as interações jogam, antes de mais nada, com relações interpessoais, ritualizadas socialmente" (Kebrat-Orechioni in Amossy, 2005: 13).

O mesmo pode-se afirmar acerca da argumentação, uma vez que esta termina por, como o conhecimento do auditório, auxiliar na construção do ethos e também foi foco de estudo da Antiga Retórica. Porém, no século XX, este elemento retórico foi igualmente resgatado por Chaïm Perelman e Lucie Olbrechts-Tyteca, no seu Tratado da argumentação: a nova retórica, publicado em 1958 (2002). Segundo outro teórico que se debruça sobre esse assunto, Philippe Breton (1999: 26), “(...) argumentar é raciocinar, propor uma opinião aos outros dandoIhes boas razões para aderir a ela". Partindo-se desse raciocínio, o orador usa mais esse componente para auxiliá-lo no seu intento persuasivo e na construção do ethos.

Santana Neto (2005: 22) lembra que:

"Os três componentes da persuasão congregam os três lugares complementares que concorrem para todo movimento argumentativo. Na realidade, o tipo de argumento utilizado intervém também na construção e na imagem do orador, na exteriorização de seus sentimentos e em sua capacidade de inflamar o auditório".

Vale salientar um tipo de argumento que será importante para a análise proposta neste trabalho, o qual é o pragmático. Esse deve ser estruturado "(...) sobre a pertinência, a necessidade ou a legitimidade de um ato, de uma instituição, em função das conseqüências esperadas” (Breton, 1999: 128), tendo sempre que existir esse vínculo constante e permanente entre o fato realizado e os efeitos deste. De acordo com Abreu (2004: 60), “(...) 
para que um argumento pragmático funcione é preciso que o auditório concorde com o valor da conseqüência".

Para fundamentar a análise da produção textual escolhida para ser estudada neste artigo, alguns conceitos da Análise do Discurso, de linha francesa, ainda devem ser expostos para que melhor se abarque o discurso/texto.

Assim, faz-se necessário entender como um discurso se processa e é construído. Sabe-se, então, que todo discurso tem condições de produção específicas e estas são chamadas de enunciações, as quais determinam a elocução de um determinado discurso e não de outros, uma vez que se referem a "(...) determinadas circunstâncias, a saber, o contexto histórico-ideológico e as representações que o sujeito, a partir da posição que ocupa ao enunciar, faz de seu interlocutor, de si mesmo, do próprio discurso etc." (Mussalim; Bentes, 2001: 116). Para Ducrot (1987: 168), “(...) a enunciação é o acontecimento constituído pelo aparecimento de um enunciado", sendo esse um momento único definido no tempo e no espaço, uma vez que o enunciado não existia antes de ser proferido e não existirá mais depois disso. Assim, a enunciação seria um ato que termina por gerar um produto: o enunciado. Portanto, aquela e este serão os estudados detalhadamente em cada uma das matérias escolhidas para se empreender essa pesquisa, para que se possa chegar no ethos, salientandose ainda que cada produção jornalística selecionada é um enunciado resultante de uma enunciação.

Toda enunciação pressupõe uma situação de comunicação e uma cena de enunciação. A primeira

“(...) refere-se ao conjunto de condições que organizam a emissão de um ato de linguagem. Essas condições permitem, por exemplo, saber a que ou a quem remetem os pronomes e certos advérbios (...), e desambigüizar, eventualmente, um enunciado polissêmico (...); descobrir o implícito que se encontra escondido nos atos de fala nos quais o explícito é diferente (...); descobrir o sentido de um enunciado de acordo como o posicionamento ideológico daquele que o pronuncia (...). Desse modo, para interpretar um enunciado, é preciso conhecer um certo número de dados que desempenhem o papel de instruções situacionais, sem os quais haveria risco de mal-entendidos ou de incompreensão" (Maingueneau; Charaudeau, 2004: 450-451).

Segundo Kusch (2003: 69),

"O sistema organizacional se viabiliza graças ao sistema de comunicação nele existente, que permitirá sua contínua realimentação e sua sobrevivência. Caso contrário, entrará num processo de entropia e morte. Daí a imprescindibilidade da comunicação para uma organização social".

Assim, para viabilizar esse sistema, as empresas produzem textos que espelham o seu discurso, o qual termina por construir a imagem dessas corporações. Para Tereza Halliday (2009: 32), o discurso empresarial seria "(...) o conjunto de práticas linguísticas, semânticas e retóricas das pessoas jurídicas". Essa mesma teórica entende a

“(...) comunicação organizacional como construção simbólica da realidade (...) Salienta também que as organizações usam palavras e outros símbolos para informar, apresentar razões e justificar-se, construindo um discurso legitimizante, sintonizado com os interesses e valores de seus públicos. Nesta abordagem [...], o discurso organizacional é tratado como ação e como recurso, tão importante quanto os econômicos, tecnológicos e humanos. Além disso, ele agrega valor na medida em que contribui para aumentar o poder da organização entre seus interlocutores" (Halliday, 2009: 31).

Halliday (2009: 32) destaca que "(...) os textos produzidos pelas organizações - difundidos seja por meio de fala, seja por escrito - são a manifestação primordial de seu discurso e a unidade discursiva preferida pelos analistas".

Ainda seguindo esse raciocínio, Halliday (2009: 33) afirma que "(...) os significados produzidos e expressos por uma organização agregam valor ao seu cabedal, isto é, ao conjunto de bens materiais e imateriais, além de formarem o patrimônio organizacional".

Urge igualmente entender quem são os responsáveis pela produção e recepção desses discursos. Num dado discurso, acerca das personagens as quais se reportam ao orador, usando-se a visão de Ducrot (1987: 193), podem-se identificar três entidades, as quais são: o "sujeito falante" ou "autor empírico do enunciado" (produtor 
exterior ao sentido do enunciado), o "locutor" ("ser que, no próprio sentido do enunciado, é apresentado como seu responsável", equivalendo ao "ser de discurso") e há ainda o "enunciador" (ser de pura enunciação, que determina o ponto de vista a partir do qual os acontecimentos são apresentados, podendo ser denominado de "sujeito da enunciação", ou seja, é um efeito do enunciado). Contrapondo-se às figuras produtoras do discurso, existem aquelas que respondem pela recepção desse, são as seguintes: "co-enunciador" (correlativo de enunciador, uma vez que a enunciação é igualmente uma co-enunciação, na qual dois indivíduos desempenham papéis ativos), "alocutário" (refere-se ao que poderia denominar de "destinatário direto" do discurso, a eles o locutor atribui um "lugar" enunciativo) e "leitor" (seria um co-enunciador virtual, uma vez que o diálogo deste com o "escritor"/sujeito falante é mais da ordem informativa do que da ordem do linguísticocomunicativo). Este último ainda pode ser considerado a partir de dois ângulos diferentes: (1) como o público efetivo de um texto, ou (2) como o público que esse texto implica por suas características, ou seja, os traços textuais permitem reconstruir uma representação que o "escritor" teve de criar daqueles que iriam ler o seu texto.

Cabe ainda afirmar, ao se falar em "cena", que os analistas do discurso, inspirados nas correntes pragmáticas, recorrem à metáfora teatral estoica, "(...) segundo a qual a sociedade seria um vasto teatro onde um papel seria atribuído a cada um" (Maingueneau, 2000: 31). Pode-se, dessa forma, dizer que a língua comporta todo um arsenal de relações inter-humanas, isto é, toda uma coleção de papéis os quais o locutor pode escolher para si próprio, apresentando-se a partir desses como enunciador(es), e impor ao destinatário, bem como, "(...) utiliza-se, mais particularmente, a noção de 'cena' para a representação que um discurso faz de sua própria situação de enunciação" (Maingueneau; Charaudeau, 2004: 95).

$\mathrm{Na}$ Análise do Discurso de linha francesa, além do conceito de "papel", tem-se ainda o de "lugar", que visa enfatizar a preeminência e preexistência da topografia social sobre os falantes que aí venham a se inscrever. A especificidade desse "repousa sobre o traço essencial segundo o qual cada um alcança sua identidade a partir e no interior de um sistema de lugares" (Maingueneau, 1997: 33). Na visão de Foucault (2002), o "lugar" termina por determinar qual é a posição que pode e deve ocupar cada indivíduo para dela ser sujeito enunciativo. Esse conceito é crucial a partir do instante em que se pensa nele em termos das formações discursivas (FD), as quais "determinam o que se pode e deve ser dito a partir de uma conjuntura dada" (Maingueneau; Charaudeau, 2004: 241). Para Michel Foucault (in Maingueneau, 1997: 14), uma FD é "um conjunto de regras autônomas, históricas, sempre determinadas no tempo e no espaço que definiram em uma época dada, e para uma área social, econômica, geográfica ou linguística dada, as condições de exercício da função enunciativa".

Partindo-se desses conceitos, sabe-se igualmente que, quando passam de uma FD para outra, as palavras alteram o seu sentido, uma vez que, na visão de Ducrot (1987: 172), o sentido "(...) é uma representação da enunciação". Daí se poder falar em "efeito de sentido", que é a infinita variedade de valores de que se podem revestir os itens lexicais no discurso, em função do contexto/da FD em que esses estejam inscritos. Dessa forma, pode-se afirmar que os efeitos de sentido nada mais são do que o resultado dos valores atribuídos pelo discurso ao significado previamente estabelecidos na língua.

\section{Orlandi (2002: 42) alerta que}

“(...) o sentido não existe em si, mas é determinado pelas posições ideológicas colocadas em jogo no processo sócio-histórico em que as palavras são produzidas. As palavras mudam de sentido segundo as posições daqueles que as empregam. Elas "tiram" seu sentido dessas posições, isto é, em relação à formações ideológicas nas quais essas posições se inscrevem".

Com isso, cabe um esclarecimento acerca do que vem a ser uma formação ideológica (FI). Para a AD, seria o “(...) confronto de forças em um dado momento histórico" (Mussalim, 2001: 124).

Ainda se tem que fazer algumas considerações sobre o sentido produzido nos enunciados, lanni (2000: 218) declara que

"(...) a palavra pode ser, simultaneamente, erma e plena de sentidos, dependendo do modo pelo qual é escrita ou falada, bem como lida ou ouvida. Em geral, no entanto, carrega consigo muita experiência, toda uma existência. Nenhuma palavra flutua solta no espaço e no tempo, solitária, carente. Tanto se articula com outras 
com se enraíza mais ou menos densamente na vida de uns e outros".

Enquanto que Halliday (2009: 33) afirma que “(...) os significados produzidos e expressos por uma organização agregam valor ao seu cabedal, isto é, ao conjunto de bens materiais e imateriais, além de formarem o patrimônio organizacional".

Afirmado isso, pode-se pensar na subjetividade enunciativa. Sobre essa, Benveniste (1995: 286) advoga que essa "(...) é a capacidade do locutor para se propor como 'sujeito". Também aponta as formas disponibilizadas pela língua para esse fim: o pronome "eu" - que é a própria consciência de si mesmo; o pronome "tu" - que advém do contraste com o "eu" (esses dois constituem a denominada "intersubjetividade"); as formas temporais; as indicadoras da dêixes e os verbos modalizadores conjugados na primeira pessoa.

Mais tarde, Kerbrat-Orecchioni (1999) ampliou esse inventário de marcadores de subjetividade ao acrescentar, aos já existentes, uma classificação que divide os adjetivos em: "objetivos", aqueles que visam apenas descrever, e "subjetivos", formas indicadoras da subjetividade enunciativa. Este ainda se subdividem em: "afetivos" (elementos que terminam por enunciar, simultaneamente, uma propriedade do objeto que determinam e uma reação emocional do sujeito falante frente a esse objeto); "avaliativos axiológico" (que implicam uma dupla norma, relacionada ao objeto a que se aplicam e ao sistema de avaliação do enunciador, tendo o caráter valorativo mais destacado do que as características desse objeto); e "avaliativos não-axiológicos" (cujo emprego depende da idéia que o enunciador faz da norma de avaliação adequada àquela categoria de objetos; sendo que, desses três tipos de adjetivos, esse último é o que tem o menor caráter subjetivo).

Também para se empreender um estudo sobre discurso, não se pode esquecer da situação enunciativa em que esse acontece, pois se sabe que toda enunciação pressupõe uma situação de enunciação, que se refere "(...) ao conjunto de condições que organizam a emissão de um ato de linguagem" (Maingueneau; Charaudeau, 2004: 450). Ou seja, "(...) todo enunciado se realiza numa situação definida pelas coordenadas espaçotemporais: o sujeito refere o seu enunciado ao momento da enunciação, aos participantes na comunicação e ao lugar em que o enunciado se produz" (Dubois et al., 1999: 168).

Sobre a embreagem, essa estaria exposta nas marcas linguísticas por meio das quais se manifesta a enunciação, visto que os enunciados têm como ponto de referência o próprio ato de enunciar, do qual são produto. Porém, só algumas características desses são levadas em consideração, aquelas que são definidoras da situação de enunciação lingüística, que são: enunciadores e co-enunciadores, o momento e o lugar da enunciação. Esses elementos formam a denominada embreagem textual à situação de enunciação, sendo apresentadas comumentes pelo "EU" e "TU" - embreagem de pessoa; pelo "agora" - embreagem de tempo; e pelo "aqui" - embreagem de espaço.

Ainda resta uma reflexão acerca da questão do tempo. Benveniste (1989: 75-76) apresenta a idéia de "tempo linguístico", cuja singularidade está nesse ser “(...) organicamente ligado ao exercício da fala, o fato de se definir e de se organizar como função do discurso (...) Cada vez que um locutor emprega a forma gramatical do "presente" (...), ele situa o acontecimento como contemporâneo da instância do discurso que o menciona (...)".

Pode-se dizer que todo discurso instaura um "agora", que equivale ao momento da enunciação, o qual transcorre no tempo presente linguístico, em que existe uma "concomitância" entre o evento narrado e o momento da narração e aquele em que acontece a "não-concomitância", a qual se divide em "anterioridade" e "posterioridade" ao "agora".

Fiorin (2002: 145) afirma que a temporalidade instaurada pela língua refere-se também às relações de sucessividade entre estados e transformações representados no próprio texto. Com isso, esse mesmo teórico (pp. 146) nota que existem na língua dois sistemas temporais: o enunciativo - relacionado diretamente ao momento da enunciação (ME), organizado em função do presente que já está implícito na enunciação; e o enuncivo - ordenado em função de momentos de referência (MR), instalados no enunciado. A esses dois sistemas se devem aplicar as categorias de "concomitância" $X$ "não-concomitância" ("anterioridade" X "posterioridade") do "agora", com isso, tem-se três momentos de referência: o concomitante, o anterior e o posterior ao instante da enunciação. Sabe-se que quando o momento de referência e o de enunciação são coincidentes, usa-se o sistema enunciativo. Mas, quando a produção e a recepção de um texto não acontecem 
simultaneamente, esse momento de referência tem de ser explicitado. Além dos momentos de enunciação e o de referência, tem-se ainda o do acontecimento (MA), o qual se refere aos estados e transformações e está ordenado em relação aos diferentes momentos de referência.

Pode-se visualizar, esquematicamente, como o sistema temporal da língua portuguesa pode ser apresentado nos discursos a partir da llustração 2.

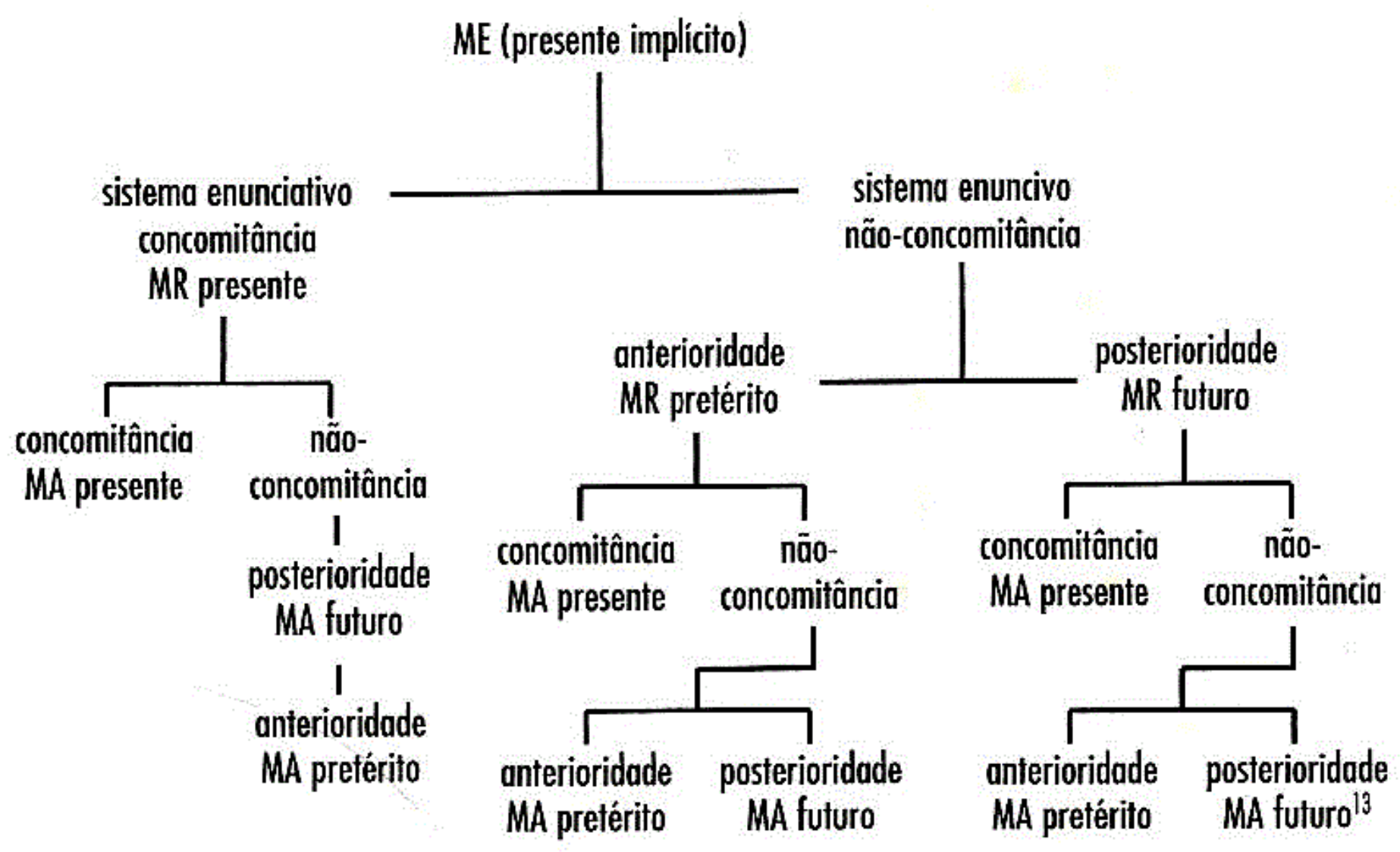

Ilustração 2 - Sistema temporal da língua portuguesa

Fonte: Fiorin (2002: 146)

Selecionou-se como produção textual a ser estudada discursivamente uma nota de uma revista empresarial. Essa escolha deu-se por se tratar de um texto jornalístico noticioso, de utilidade dentro e até fora da empresa, escrito de maneira impessoal e publicado sem assinatura, referente a um assunto tido como importante e relevante para o momento atual. De acordo com Rabaça e Barbosa (1987: 512), a nota jornalística é uma "(...) pequena notícia destinada à informação rápida. Caracteriza-se por extrema brevidade e concisão (...) Destinase a prestar esclarecimento ao público, firmando a posição da instituição como respeito a determinado fato".

Araújo e Souza (2004: 134) advogam que uma nota "(...) corresponde ao relato de acontecimento que estão em processo de configuração". Também foi escolhido esse tipo de texto jornalístico por se tratar de um texto comum na vida cotidiana das pessoas e sua importância em termos de conteúdo para o momento presente.

Cabe ainda uma ressalva, a de que essa publicação selecionada destina-se ao colaborador interno da empresa em questão. Portanto, todo discurso será voltado para esse público leitor.

\section{A NOTA}

A nota jornalística estudada (Unibanco, 2007: 18) foi retirada da Revista Unibanco, número 341, publicada em março de 2007. 


\section{EXTRATO}

Unibanco em revista

Comunicação

\section{Interatividade}

5 O Voz Ativa passou por uma grande reformulação no início de 2006 e se transformou na principal ferramenta de interação entre colaboradores e 0 Unibanco. O canal permite o envio de opiniões, críticas e sugestões sobre diversos temas, além, de disponibilizar uma área com perguntas mais freqüentes e acompanhamento de status da mensagem. Os números

10 comprovam a credibilidade e eficácia do Voz Ativa. No ano passado, foram ehviadas cerca de 14 mil mensagens. Destas $99 \%$ foram respondidas, sendo $87 \%$ delas no prazo de até sete dias. Além disso, 95\% dos colaboradores que utilizaram o canal disseram estar satisfeitos com a prestação de serviços.

Ilustração 3 - Nota jornalística da Revista Unibanco

Fonte: Unibanco (2007: 18)

Cabe mencionar que, em 3 novembro de 2008, Itaú e Unibanco anunciaram a fusão das operações financeiras, formando o Itaú Unibanco Banco Múltiplo, a maior holding financeira do hemisfério sul, e entre as vinte maiores do mundo. Devido a esse processo de fusão, as agências do Unibanco foram recebendo aos poucos as características "Itaú" até o final de 2010, quando a marca "Unibanco" deixou definitivamente de ser utilizada, bem como a referida revista deixou de ser publicada.

O Unibanco possuia uma das revistas corporativas de melhor diagramação e respeito com os seu público de interesse, que no caso era o interno. A Revista Unibanco era uma comunicação dirigida escrita detentora de alto nível de elaboração textual e confecção.

\section{AANÁLISE PROPRIAMENTE DITA}

Para efeito de cunho metodológico, cabe uma ressalva inicial. Com a finalidade de empreender a análise proposta neste artigo, os pesquisadores farão citações retiradas da nota jornalística da Revista Unibanco, explicitada no item 3 deste documento, e indicacarão a linha (I.) em que estas se encontram. Assim, toda vez que aparecer "I.", nesta seção, esse referenciar-se-á a linha em que está localizada determinada citação da nota em estudo.

Visando observar o discurso que circula nas empresas sobre canais de comunicação, foram levantados os elementos os quais servem para construir o ethos, bem como foi estudada a argumentação usada com fins de convencimento discursivo.

Escolheu-se, para tanto, como produção textual a ser analisada, como já foi mencionado, uma nota da revista empresarial do Unibanco S.A. - a Revista Unibanco (RU). Nessa nota, o ethos adotado é o de uma empresa preocupada em disponibilizar para os seus funcionários um canal/ferramenta de comunicação que possibilite “(...) o envio de opiniões, críticas e sugestões sobre diversos temas (...)" (I. 7-8), ou seja, de uma corporação competente e ciente de que ouvir o seu público leitor, no caso o colaborador interno, na atualidade, é imprescindível, bem como se mostra inquieta e disposta a ouvir/colher as opiniões/pontos de vista que esse auditório pode expor sobre sua própria prática.

Assim, observa-se que as condições de produção discursiva da nota selecionada eram propícias a se verbalizar e instaurar uma ferramenta de estabelecimento de diálogo entre o Unibanco e seu público interno.

Como estratégia discursiva, observa-se que o Voz Ativa é a face da boa imagem constuída para a ferramenta, sendo partilhável para o Unibanco enquanto instituição bancária que se preocupa em ouvir os funcionários. Também se observa que esse banco adquire o papel de uma empresa que se preocupa em ouvir seu público interno através desse canal de comunicação. 
Observar-se-á a seguir como esse ethos organizacional se apresentou tanto em nível argumental como no linguístico. Começa-se, então, esta investigação com o estudo dos argumentos e a das estratégias comunicativas usadas nesta produção textual.

Essa matéria foi estruturada em um único parágrafo (geralmente, essa é a estrutura de formato de uma nota jornalística), o qual foi construído dentro de um argumento pragmático que, só para lembrar o que já foi mencionado, "(...) permite apreciar um ato ou um acontecimento consoante suas conseqüências favoráveis ou desfavoráveis" (Perelman; Olbrechts-tyteca, 2002: 303) desse. "A partir do momento em que a ligação fatoconseqüência é constatada, a argumentação se torna válida” (Perelman; Olbrechts-tyteca, 2002: 304). Dessa forma, Perelman e Olbrechts-Tyteca (2002: 76) advogam que a consequência funciona, neste caso, como uma condição do fato e termina por favorecer a defesa desse frente a uma possível desconfiança ou má vontade por parte do auditório.

Aqui, o fato é que o Voz Ativa passou por ser a "(...) principal ferramenta de interação entre colaboradores e o Unibanco" (I. 6), funcionando como uma Ouvidoria. Para comprovar isso, como não poderia deixar de existir na sociedade contemporânea, ou melhor, no mundo empresarial e, principalmente, no bancário, o argumento supra citado vem acompanhado de estatísticas, isto é, da "voz" incontestável dos números, os quais atestam essa idéia e que são resultados/conseqüências do fato mencionado na abertura do texto.

Percebe-se que todo o argumento exposto foi colocado para tornar os funcionários convictos de que suas opiniões são de suma importância para a empresa, bem como convencê-los de que são o público razão desta empresa ter o sucesso que tem e que esta quer "abrir" canais que sejam notoriamente eficientes (daí, a reformulação dessa ferramenta comunicacional e dos números expostos na produção em questão) e que possibilitem o constante diálogo. Com isso, igualmente se chega ao discurso do Comunicador/Ouvidor, o qual, aqui, ouve e responde em tempo hábil todas as mensagens que lhes chegam em mão, bem como serve de "termômetro" da qualidade das relações existentes na organização.

Após a análise do argumento utilizado na nota selecionada, passa-se ao exame dos dados linguísticos para a construção do sentido e do ethos.

Os enunciadores, no texto analisado, sofreram um total apagamento tanto em nível de "EU" quanto de "TU". Isso ocorre de maneira proposital e se dá para conferir uma maior autenticidade/neutralidade àquilo que está sendo proferido. Percebe-se que o uso desse recurso é muito difundido nas redações jornalísticas, fato esse igualmente comprovado nesta produção noticiosa, uma vez que essa nota se utiliza desse artifício que termina por marcar a neutralidade enunciativa, igualmente, preconizada e defendida nos cursos e labutar do Jornalismo.

Acerca dos embreantes de espaço, observou-se que esses não foram encontrados, isto é, não há itens linguísticos que marquem o espaço em que ocorre a situação enunciativa. Porém, pelo conhecimento de mundo do leitor acerca da feitura dos textos jornalísticos, sabe-se que a enunciação desta nota, como de qualquer texto produzido em uma redação de jornal, acontece neste local, no momento em que se está escrevendo a produção textual, tendo, portanto, o momento de referência - uma vez que este se alonga até a leitura do texto - mais longo que o da enunciação - momento da produção/elaboração, contudo, pode-se dizer que aquele é simultâneo também a este, em algum instante dessa prolongada faixa de tempo.

Partindo-se para os embreantes de tempos, ou seja, aquelas palavras ou expressões que ancoram a situação enunciativa dentro de um determinado tempo, pode-se afirmar que este texto possui duas expressões que marcam o momento do acontecimento como pretérito e como não-concomitância ao momento de referência presente, são elas: "no início de 2006" (I. 5) e "no ano passado" (I. 10).

Quanto a esses tempos verbais, inicia-se a análise pelos plenos, ou seja, por aqueles que se referem ao modo indicativo (Quadro 1), pode-se afirmar que os enunciados foram produzidos no presente dêitico o qual permite situar a enunciação entre passado (fatos anteriores àqueles que estão sendo apresentados) e o futuro (acontecimentos posteriores àqueles que estão sendo relatados). Esse presente, explicitamente, só aparece em um enunciado, porém serve para organizar toda a situação exposta nesta nota: o texto está sento construído no presente, portanto, o que importa é o que a ferramenta se tornou no momento atual, todos os tempos pretéritos, a maioria quase que absoluta, servem, portanto, para fundamentar a narrativa. 


\begin{tabular}{|c|c|}
\hline Concomitância MR Presente & Linhas \\
\hline Concomitância MA Presente & permite (7) \\
\hline \begin{tabular}{l|l|l|l|} 
Não-Concomitância & Anterioridade MA Pretérito
\end{tabular} & $\begin{array}{l}\text { passou (5); transformou (6); comprovam } \\
\text { (10); utilizaram (13); disseram (13) }\end{array}$ \\
\hline
\end{tabular}

Ressalta-se ainda que foram colocados, num Quadro (o número 2), os semitempos os quais só expressam aspecto quando ligados aos tempos plenos que terminam por Ihes determinar a ancoragem temporal. Com isso, como já foi afirmado anteriormente, esses também servem para contribuir com a embreagem temporal discursiva, reforçando num resultado similar ao do Quadro 1. A forma de apresentação adotada para essa situação peculiar foi a seguinte: a forma plena aparece entre colchetes, o semitempo em negrito e a linha citada é a deste.

Quadro 2 - Semitempos - Sistema Enunciativo

\begin{tabular}{|c|c|c|}
\hline Concomitância MR & resente & Linhas \\
\hline Concomitância MA & resente & [permite] disponibilizar (8) \\
\hline Não-Concomitância & Anterioridade MA Pretérito & $\begin{array}{l}\text { foram enviadas } \quad(10-11) ; \quad \text { foram } \\
\text { respondidas (11); disseram estar (13) }\end{array}$ \\
\hline
\end{tabular}

Empreendidas essas observações sobre a embreagem de tempo, pode-se concluir que, apesar da aparente total objetividade/neutralidade existente nesta nota jornalística, há um "EU" representando a percepção avaliativa e, portanto, subjetiva do Unibanco frente à ferramenta apresentada - o Voz Ativa - que se dirige a um "TU" apontado como o público leitor dessa publicação, a qual mobiliza expressões e marcas temporais (Quadros 1 e 2).

Ainda resta a investigação acerca dos adjetivos e as locuções adjetivas (Quadros 3 e 4), observou-se a não existência de ambos os fatos gramaticais citados, indicando valoração afetiva, provando, dessa maneira, mais uma vez a tentativa de suprimir/apagar totalmente a subjetividade enunciativa. Percebeu-se igualmente que, para os adjetivos, há três registros dos avaliativos axiológicos e dois dos não-axiológicos. Essas marcas qualificadoras demonstram, ainda que minimamente, a presença subjetiva do enunciador, uma vez que esses tipos de qualificadores estão diretamente relacionados ao sistema avaliativo desse sujeito, comprovando mais uma vez que não existe produção textual destituída totalmente de subjetividade. A presença maciça de locuções adjetivas descritivas e a de quatro registros de adjetivos com esse valor apontam para a tentativa de mais uma vez impessoalizar inteiramente o enunciador textual como já foi salientado anteriormente, ou seja, busca-se apresentar o discurso da maneira mais objetiva possível, mesmo que esse objetivo inicial seja traído/desviado diminutamente pelo uso de algumas palavras ou expressões também já explicitadas.

Quadro 3 - Classificaçăo dos Adjetivos

\begin{tabular}{l|l}
\hline CLASSIFICAÇÁO DOS ADJETIVOS & \multicolumn{1}{c}{ LINHAS } \\
\hline Objetivos I Descritivos & diversos (8) mais frequentes (8-9); passado (10) \\
\hline Avaliativos năo-axiológicos & grande (5); principal (6); \\
\hline Avaliativos axiológicos & Ativa $(5,10) ;$ satisfeitos (13) \\
\hline
\end{tabular}


Como se vem presenciando nos últimos anos, quase toda produção jornalística está sendo publicada sem a devida revisão ortográfica e gramatical. Com a nota analisada não ocorreu diferente. O referido texto carece de uma revisão da língua vernacular. Aqui, o que se presenciou foi a não utilização adequada da pontuação. Fato que os pesquisadores entende como não adequado para publicações do porte da revista em questão, uma vez que esta visa a formação da imagem institucional junto a um dos públicos preferenciais da empresa em questão, o funcionário. Cabendo ainda uma ressalva a de que se uma revista pode "errar" no uso da língua vernacular, o público leitor também o pode fazê-lo.

\section{CONCLUSÕES}

Após a análise empreendida, observou-se que, na produção textual escolhida, foi construído o ethos que encarna o perfil de uma oraganização ciente da sua responsabilidade junto ao seu público interno, empresa essa que se preocupa com a opinião do seu colaborador interno, daí se ter criado um canal de comunicação direto com este. Esses canais vêm se proliferando em todas as corporações, ganhado força e servindo para demonstrar o respeito organizacional pela voz dos seus públicos preferenciais, entre esses está o funcionário. Ou seja, aqui o que se busca, cada vez mais, é a valorização e o acesso a informações através de um veículo de comunicação interna os quais tentam auxiliar a melhoria das relações dos funcionários entre si e com própria empresa.

Portanto, o que foi observado é que o ethos do Unibanco é o de uma organização que se preocupa com a sua imagem junto a sua equipe de funcionários. Como também é uma empresa cujo preocupação seria a criação do senso de equipe, de corporação, não desprezando as opiniões e a individualidade dos seus colaboradores, daí a criação do canal de comunicação com esses.

Pode-se ainda afirmar que o ethos que foi construído serve de forma preponderante para persuadir o coenunciador do discurso, trazendo esse para perto da organização. Esse elemento retórico foi elaborado a partir tanto das escolhas linguísticas quanto da dos argumentos.

Salienta-se que os pesquisadores advogam que análises, como a empreendida neste trabalho, podem auxiliar os profissionais das Letras - uma vez que esses lidam com a produção e recepção de produções textuais em geral, bem como fazem com que aulas ministradas por esses seja algo vivo e com que os estudantes do vernáculo entendam que este é um instrumento o qual o auxiliará no seu dia a dia como cidadão de um mundo cada vez mais comunicacional e persuasivo, como também os da área da Comunicação Social (CS) (principalmente os da área das Relações Públicas (RP) por trabalharem nas/para as empresas), pois conferem, aos que desempenham essa atividade, uma maior consciência do uso adequado de ferramentas que possibilitem uma persuasão às ideias apresentadas em seus textos. Podendo ainda ajudar na prática dos administradores, principalmente os da área de Recursos Humanos, uma vez que saberão como atingir seus colaboradores internos e os problemas que os afligem.

Por último, ainda se deve afirmar que as produções textuais da área empresarial, como o que foi analisado neste breve trabalho, são um rico material de estudo não só para os profissionais da CS/RP como também para os das Letras. Saber como eles são elaborados e como devem ser lidos, principalmente, usando-se as pistas neles deixadas pelo enunciador, deve ser tarefa desses dois profissionais - um tendo consciência do que está produzindo e o outro tendo capacidade de ler este tipo de material - e essa é a pequena contribuição deixada 
por este estudo.

\section{REFERÊNCIAS BIBLIOGRÁFICAS}

ABREU, A. S. (2004): A arte de argumentar: gerenciando razão e emoção. 7 edición. Cotia, Brasil: Ateliê Editorial.

ADAM, J.M. (2005): Imagens de si e esquematização do orador: Pétain e De Gaulle em junho de 1940. En: AMOSSY, R. (Org.) (2005). Imagens de si no discurso: a construção do ethos. São Paulo: Contexto. pp. 93-114. AMOSSY, R.: Da noção retórica de ethos à análise do discurso. En: AMOSSY, R. (Org.) (2005): Imagens de si no discurso: a construção do ethos. São Paulo: Contexto. pp. 9-28.

ARAÚJO, E. R.; SOUZA, E. C. (2004): Obras jornalísticas: uma síntese. edición. Brasília: Vestcon.

ARISTÓTELES ([V a.C.] 1998): Retórica. Trad. Manuel Alexandre Júnior et al. Lisboa: Imprensa. Nacional/Casa da Moeda.

BENVENISTE, E. (1995): Problemas de lingüística geral I. Trad. Maria da Glória Novak e Maria Luisa Neri. 4 edición. Campinas, Brasil: Pontes.

- (1989): Problemas de lingüística geral II. Trad. Eduardo Guimarães et al. Campinas, Brasil: Pontes.

BRETON, PP. (1999): A argumentação na comunicação. Trad. Viviane Ribeiro. Bauru, Brasil: EDUSC.

DUBOIS, J. et al. (1999): Dicionário de lingüística. Trad. Frederico Pessoa de Barros et al. 7 edición. São Paulo, Brasil: Cultrix.

DUCROT, O. (1987): O dizer e o dito. Trad. Eduardo Guimarães. Campinas, Brasil: Pontes.

FIORIN, J. L. (2002): As astúcias da enunciação: as categorias de pessoa, espaço e tempo . 2 edición. São Paulo, Brasil: Ática.

KERBRAT-ORECCHIONI, C. (1993): La enunciación: de la subjetividade en el language. Trad. Gladys Ânfora e Emma Gregores. 2 edición. Buenos Aires: Edicial.

KUNSCH, M. M. K. (2003): Planejamento de relações públicas na comunicação integrada. 4. ed. rev. atual. ampl. São Paulo: Summus.

MAINGUENEAU, D.; CHARAUDEAU, PP. (2004): Dicionário de análise do discurso. Coord. Trad. Fabiana Komesu. São Paulo, Brasil: Contexto.

MCLUHAN, M.; FIORE Q. (1969): Os meios são as massa-gens. Trad. Ivan Pedro de Martins. Rio de Janeiro, Brasil: Record.

MEYER, M.; CARRILHO, M. M.; TIMMERMANS, B. (2002): História da retórica. Lisboa: Temas e Debates.

MUSSALIM, F.; BENTES, A. C. (Org.) (2001): Introdução à lingüística: domínio e fronteira. vol. 2. São Paulo, Brasil: Cortez.

PERELMAN, C.; OLBRECHTS-TYTECA, L. (2002): Tratado da argumentação: a nova retórica. Trad. Maria Ermantina Galvão G. Pereira. São Paulo, Brasil: Martins Fontes.

RABAÇA, C. A.; BARBOSA, G. G. (1987): Dicionário de comunicação. São Paulo, Brasil: Ática.

SANTANA NETO, J. A. (2005): Processos argumentativos: estudo retórico de textos didáticos. Salvador, Brasil: Quarteto. 
UNIBANCO (2007): “Unibanco em revista: comunicação: interatividade”. Revista Unibanco, n 341 (Marzo 2007), pp. 18.

\section{BIOGRAFIA}

Marta Cardoso de Andrade é relações-públicas, professora e líder de pesquisa CNPq. Doutora e Mestra em Letras pela UFBA, com foco de pesquisa na área da Comunicação Organizacional. Especialista em Avaliação (UNEB) e em Gramática e Texto da Língua Portuguesa (UNIFACS). Licenciada Plena em Língua Portuguesa (UNEB). Associada à Intercom, à Abrapcorp, à Abralin, ao Gelne e ao IBRI. Consultora nas áreas de Comunicação Corporativa e Discurso Empresarial.

Hélder Uzêda Castro é administrador, professor e pesquisador CNPq. Doutorando em Desenvolvimento Regional e Urbano e Mestre em Administração pela UNIFACS, com foco de pesquisa nas áreas de Governança Corporativa e Tributária em Centros de Serviços Compartilhados; MBA em Gestão Empresarial (FGV) e Especialista em Planejamento e Gestão de Projetos Logísticos (FCA). Associado ao IBGC (extensão em Melhores Práticas de GC).

Ámbitos. Revista Internacional de Comunicación, n.31, edición de invierno, 2016.

Recibido: 26/03/2015

Aprobado: 25/04/2015 